\title{
Italian version of Nursing Students' Perception of Instructor Caring (I-NSPIC): assessment of reliability and validity
}

\author{
C. Arrigoni ${ }^{1 *}$, M. Puci ${ }^{2}$, A. M. Grugnetti ${ }^{1,3^{*}}$ D, L. Collivasone ${ }^{4}$, E. Fenizia ${ }^{5}$, P. Borrelli ${ }^{2}$, E. Vellone ${ }^{5}$, R. Alvaro ${ }^{5}$, \\ M. Piredda ${ }^{6}$ and M. G. De Marinis ${ }^{6}$
}

\begin{abstract}
Background: Clinical experience is an essential component of nursing education since it provides students with the opportunity to construct and develop clinical competencies. Instructor caring is a pivotal facilitator at the forefront of clinical education, playing a key and complex educating role in clinical sectors. For these reasons the aims of this study was to assess the validity and reliability of the Italian version of NSPIC (I-NSPIC).

Methods: A validation multicentre study was conducted in three different Italian universities. A total of 333 nursing students were enrolled in the 2014/2015 academic year. Exploratory factor analysis (EFA) with oblique rotation was performed to test the construct validity of I-NSPIC. The Cronbach's alpha coefficient and test retest via Intraclass Correlation Coefficient (ICC) analyses were done to assess the internal consistency and stability of the scale. A Spearman's correlation with another scale (CLES-T) was used to examine the concurrent validities.

Results: Four factors (control versus flexibility, supportive learning climate, confidence through caring, appreciation of life meaning and respectful sharing) were identified in EFA. The Cronbach's alpha value showed that I-NSPIC was a reliable instrument $(a=0.94)$ and the ICC coefficient was satisfactory.

Conclusion: The I-NSPIC is a valid instrument for assessing the perception of instructor caring in Italian nursing students. It may also prove helpful in promoting the caring ability of nursing students and in increasing the caring interactions in the relationship between instructor and nursing students.

The knowledge emerged from this study provide important insight in developing effective training strategies in the clinical training of undergraduate nursing students.
\end{abstract}

Keywords: Caring, Instructor caring, Nursing education, Clinical placement, Nursing students' perception

\section{Background}

In nursing education clinical learning and competency development are essential parts of the nursing curriculum. Clinical experience is an essential component of nursing education since it provides students with the opportunity to construct and develop clinical competencies and apply assistance to a real-world context, thereby allowing students to transfer theory into practice [1-7]. In recent years, caring is gaining scientific dignity and operational relevance

\footnotetext{
* Correspondence: cristina.arrigoni@unipv.it; annamaria.grugnetti@unipv.it; a.grugnetti@smatteo.pv.it

${ }^{1}$ Department of Public Health, Experimental and Forensic Medicine, Unit of Hygiene, University of Pavia, Via Forlanini, 2-27100 Pavia, Italy

Full list of author information is available at the end of the article
}

and is believed to be a core component of nursing education [8-14].

Jean-Watson's studies in interpersonal care emphasize that patients experience greater emotional and spiritual well-being, improved healing, and greater confidence in their relationship with health professionals when they experience a careful and participative care relationship [11].

The philosophy of the humanist paradigm is put into effect in the constructs of care, learning, participation and reflection. The movement toward this paradigm requires a transformation to a more egalitarian student-teacher relationship, thereby supporting the development of both partners, in order to understand students and facilitate their learning [15]. Therefore, instructor caring is a pivotal 
facilitator of clinical education [16, 17], serving as a model for the student $[18,19]$ and playing a key and complex educating role in clinical sectors involving many personal, interpersonal and organizational aspects [20, 21]. Moreover, instructors' caring facilitates the transition from the students' role to the nurse role [22, 23], where the instructor works with students on their learning experiences as a coach and mentor [15].

Students award a fundamental value on the clinical environment in terms of their professional development, and their instructor caring relationship, important elements for the success of their internship [16, 20, 24-26].

Emphasis on caring theories should be placed in nursing education and their application in nursing practice. Watson's theoretical framework, which focuses on interpersonal and transpersonal processes in human care, presents an effective model in understanding the concept of caring.

Watson argued that caring is the main concept in nursing education. The aim of the caring based curriculum is to provide students an overall view of caring, so that they will be able to care for the health of the individual as nurses $[8,11,13]$.

Wade and Kasper [27], feel that nursing education is an ideal place to promote and develop student caring because this is where personal involvement with others occurs.

Wade \& Kasper [27] argue that the NSPIC, based on Watson's Theory of Transpersonal Caring, is an extremely valid and reliable tool to evaluate students' perception of instructor caring. Moreover, they believe this tool can be used as an outcome of the educational process to validate the influence of support interactions between students and instructors caring about the students' caring capabilities. Caring interactions between teachers and students reflect the same nature of the nurse-patient relationship [15, 28]; therefore, nursing students' perceptions of instructor caring can reveal how nursing students learn to care for their patients. If students perceive an educational environment based on care, they will learn to become professionals [8, 25, 27].

Caring clinical environment improves well-being in nursing students, self-confidence, motivation and decreases anxiety associated with the clinical setting, facilitating the learning [8, 29-31]. Providing for a highquality clinical environment is a determining factor in improving the quality of health services [31,32].

The Nursing Students' Perception of Instructor Caring (NSPIC) instrument, based on Watson's Theory of Transpersonal Caring, was developed to evaluate nursing students' perception of instructor caring in the clinical setting in the U.S.A. [27] and subsequently validated in China [33] and Iran [34]; it was used in Italy but not validated. However, in Italy, currently no studies exist investigating the impact of instructor caring on nursing students; therefore, in this study we are interested to validate the NSPIC in Italy for assessing the perception of instructor caring among Italian nursing students. The use of this tool could help to identify the critical issues that need work to improve the quality of the nursing students' clinical learning.

The aims of this study were to translate NSPIC into Italian and to examine the reliability and validity of Italian version of NSPIC (I-NSPIC) in nursing students during clinical practice, to obtain a tool that allows us to evaluate students' perceptions of their tutor to improve the quality of clinical training in the Italian context.

\section{Methods}

\section{Study design, participants and setting}

We conducted a validation multicentre study. A sample of 333 junior (I and II years) and senior (III year) nursing students in bachelor's degree nursing programs, enrolled in the academic year 2014/2015, was randomly selected from three different Italian universities: Pavia, Roma Campus Biomedico and Roma Tor Vergata. Researchers who administered I-NSPIC were not the same as those that evaluated students in clinical laboratories. Students completed a questionnaire in a university classroom.

\section{Description of the original instrument}

NSPIC is an English questionnaire composed of 31 items divided into five dimensions: instills confidence through caring, supportive learning climate, appreciation of life's meanings, control vs flexibility, and respectful sharing. Each item is assessed on a 6-point Likert scale (responses ranged from 1 "strongly disagree" to 6 "strongly agree"). To explore the structure of the questionnaire an Exploratory Factor Analysis (EFA) was utilized; five factors were identified which explained $71.7 \%$ of the variability. NSPIC and its subscales showed very good internal consistency (NSPIC'S Cronbach alpha $=0.97$, factor $1 \alpha=0.96$, factor $2 \alpha=0.94$, factor $3 \alpha=0.89$, factor $4 \alpha=0.72$ e factor $5 \alpha=0.75$ ). The total NSPIC score ranges from 31 to 186, with higher scores representing greater perceptions of instructor caring.

\section{The screening scale translation process}

A forward-backward translation procedure was applied to establish content validity of the NSPIC scale. Firstly, the NSPIC was translated into Italian and submitted to an expert panel (four expert nurses in nursing education and research) that compared the original English version with the Italian one to ensure the semantic and cultural coherence of the items. Secondly, an English lecturer translated the Italian version back into English as a blind. Finally, the back-translate instrument and the original one were compared by the NSPIC's authors to establish the content validity of the double translated instrument (Additional file 1). The authors agreed that 
the Italian version was identical in meaning to the English version [35].

\section{Ethical considerations}

We obtained permission to validate the Italian version of the NSPIC from the authors of the original questionnaire, whom we contacted by e-mail. This study was given written approval by the University Academic Committee. All of the participants were given detailed information regarding the study aims and methodologies. The questionnaire used in this study was anonymous, and verbal consensus was obtained before its compilation.

\section{Statistical analysis}

To identify the required sample size we applied the n:p rule of thumb [36]; the $n: p$ is the minimum recommended ratio of sample size (n) to number of variables being analysed (p). Everitt [37] recommended that the n:p ratio should be at least 10. In the present study, in which $n=333$ and $p=31$, it was 10.74 , so our final sample size was in the recommended value.

Quantitative variables were summarized as mean values, standard deviations, median and interquartile range (Iqr), and qualitative variables as percentage frequencies. We assessed the factorial structure of the questionnaire by EFA, a multivariate statistical technique [38]. To determine the number of factors to retain we applied Kaiser Guttman "Eigenvalues greater than one" criterion [39-41] and Cattell's scree plot [42]. Oblique rotation (promax rotation) was used in the EFA because the factors were expected to correlate [43]. Factor loadings $\geq 0.4$ were considered as significant and were entered in the final questionnaires [44]. In order to test unidimensionality of the subscales we again ran a factor analysis. We created a score for the I-NSPIC questionnaire (sum of the responses of 31 items) and for its subscales (sum of the responses related to each dimension). Normality distribution was assessed using the Shapiro-Wilk test. To compare scores between groups we used a parametric Student $\mathrm{T}$ test for independent data or corresponding non-parametric test (Mann-Whitney or Kruskal-Wallis test); for all the analyses we considered as a significant level $p<0.05$. All analyses were conducted using STATA/SE for Windows, version 12.1 (StataCorp, college Station, TX, U.S.A.).

\section{Validity and reliability}

The validity of a questionnaire represents the degree to which it measures what it is meant to measure. There are different types of validity; criterion-related validation investigates possible associations between the examined scale and external criteria or other validated measures. Therefore, we correlate the I-NSPIC score using Spearman's correlation coefficient with the Italian version of "Clinical Learning Environment and Supervision plus nurse Teacher scale" (CLES-T) and its subscale "Supervisory relationship" (related to the content of the supervisory relationship between tutor and student) [5], which represents a gold standard Additional file 2. Prior to data collection, permission to use the CLES-T was granted by its authors through email.

Internal consistency was determined by calculating Cronbach's alpha coefficient [45]. Test-retest reliability between two subsequent administrations of the questionnaire, separated by an interval of 30 days, was assessed in a subset of the sample (25 students) using an intraclass correlation coefficient (ICC) [46].

\section{Results}

NSPIC scale and back-translation process were successful.

The demographic characteristics of the sample are summarized in Table 1.

\section{Factorial structure}

The number of eigenvalues $>1$ computed by EFA totaled four. The percentage of cumulative variability explained by a model with four dimensions is $62.92 \%$ : Factor 1 explains $42.5 \%$ of variability with an eigenvalue of 13.17 (Table 2). The subscales were unidimensional; therefore, each subscale measured only one construct. In addition, Table 2 shows factor loadings for each item.

\section{Validity}

In references to criterion-validation, Table 3 shows the Spearman's correlation coefficients between the score of INSPIC and its subscales and the CLES-T questionnaire and its subscale "Supervisory relationship". All the coefficients were significantly different from $0(p<0.05)$ (Table 3$)$.

The mean score for I-NSPIC is 113.63 (sd 19.09, range 31-186). Table 4 shows mean score, standard deviation, median and Iqr of I-NSPIC by sex, university and education.

Table 1 Sample characteristics

\begin{tabular}{ll}
\hline Variables & $\mathrm{N}(\%)$ \\
\hline Age (mean, standard deviation) & $333(100)$ \\
Sex & $22.66 \pm 4.16$ \\
Female & $269(81)$ \\
Male & $64(19)$ \\
Nationality & \\
Italian & $321(96)$ \\
Foreign & $12(4)$ \\
University & \\
Pavia & $127(36)$ \\
Rome - Campus Biomedico & $120(38)$ \\
Rome - Tor Vergata & $86(26)$ \\
Education & \\
$\quad$ Junior (I-II years) & $228(68)$ \\
Senior (III year) & $105(32)$ \\
\hline
\end{tabular}


Table 2 Exploratory factor analysis results for NSPIC $(N=333)$

\begin{tabular}{|c|c|c|c|c|}
\hline & Factor 1 & Factor 2 & Factor 3 & Factor 4 \\
\hline Eigenvalue & 13.17 & 3.96 & 1.21 & 1.16 \\
\hline$\%$ of variability & 42.50 & 12.78 & 3.90 & 3.74 \\
\hline$\%$ of cumulative variability & 42.50 & 55.28 & 59.19 & 62.92 \\
\hline \multicolumn{5}{|l|}{ Item } \\
\hline \multicolumn{5}{|l|}{ Supportive learning climate } \\
\hline 3. Instills in me a sense of hopefulness for the future. & 0.5397 & 0.4020 & & \\
\hline 8. Cares about me as a person. & 0.7399 & & & \\
\hline 13. Acknowledges his or her own limitations or mistakes. & 0.4991 & 0.3614 & & \\
\hline 15. Clearly communicates his or her expectations. & 0.5505 & & & \\
\hline 16. Serves as a trusted resource for personal problem solving. & 0.9149 & & & \\
\hline 17. Offers support during stressful times. & 0.8877 & & & \\
\hline 18. Accepts my negative feelings, while helping me to see the positive aspects. & 0.8737 & & & \\
\hline 19. Allows me to express my true feelings. & 0.8278 & & & \\
\hline 21. Inspires me to continue my knowledge and skills development. & 0.4810 & 0.4749 & & \\
\hline 27. Helps me find personal meaning in my experiences. & 0.7985 & & & \\
\hline 28. Encourages me to see others' perspectives about life. & 0.7643 & & & \\
\hline 29. Helps me understand the spiritual dimensions of life. & 0.8433 & & & \\
\hline \multicolumn{5}{|l|}{ Instills confidence through caring } \\
\hline 1. Shows genuine interest in patients and their care. & 0.3756 & 0.4895 & & \\
\hline 2. Displays kindness to me and others. & 0.3469 & 0.5330 & & \\
\hline 4. Makes me feel that I can be successful. & 0.3982 & 0.5281 & & \\
\hline 5. Helps me envision myself as a professional nurse. & 0.4253 & 0.4753 & & \\
\hline 9. Respects me as a unique individual. & 0.4179 & 0.4896 & & \\
\hline 10. Is attentive to me when we communicate. & & 0.5048 & & \\
\hline 14. Makes himself or herself available to me. & 0.4240 & 0.5166 & & \\
\hline \multicolumn{5}{|l|}{ Respectful sharing } \\
\hline 6. Makes me feel like a failure. & & & 0.9135 & \\
\hline 7. Does not believe in me. & & & 0.8143 & \\
\hline 12. Does not reveal any of his or her personal side. & & 0.4621 & 0.4796 & \\
\hline 20. Discourages independent problem solving. & & & 0.5076 & \\
\hline 22. Makes me nervous in the clinical laboratory. & & & 0.7323 & \\
\hline 23. Does not trust my judgment in the clinical laboratory. & & & 0.6130 & \\
\hline 24. Seems caught up in his or her own priorities, rather than responding to my needs. & & & 0.4581 & 0.3261 \\
\hline \multicolumn{5}{|l|}{ Control vs flexibility } \\
\hline 11. Inappropriately discloses personal information about me to others. & & & & 0.3230 \\
\hline 25. Makes demands on my time that interfere with my basic personal needs. & & & & 0.6160 \\
\hline 26. Focuses on completion of patient care tasks, rather than the patient's needs. & & & & 0.5402 \\
\hline 30. Is inflexible when faced with unexpected situations (happenings). & & & & 0.8341 \\
\hline 31. Uses grades to maintain control of students. & & & & 0.4884 \\
\hline
\end{tabular}

The differences between categories in the study were all statistically significant.

\section{Reliability}

The final version of the I-NSPIC had a Cronbach's alpha coefficient of 0.94 . Table 5 shows the Cronbach's alpha values for each of the four subscales. Test-retest analysis in 25 students showed a high degree of reliability for INSPIC: $\mathrm{ICC}=0.93, p<0.001$.

\section{Discussion}

The aim of the current study was to analyze the validity and reliability of the Italian version of the Nursing Students' Perception of Instructor Caring (I-NSPIC). 
Table 3 Spearman correlation coefficients between the scores of the NSPIC and its subscales and between the CLES-T gold standard questionnaire and its subscale Supervisory Relationship

\begin{tabular}{lll}
\hline & CLES-T & $\begin{array}{l}\text { Supervisory Relationship } \\
\text { (CLES -T subscale) }\end{array}$ \\
\hline NSPIC (sum of 31 items) & 0.54 & 0.50 \\
Supportive learning climate & 0.67 & 0.66 \\
Instills confidence through caring & 0.59 & 0.65 \\
Respectful sharing & -0.38 & -0.40 \\
Control vs flexibility & -0.25 & -0.32 \\
\hline
\end{tabular}

The results of our study show that the factor structure in the original English version cannot be assumed in Italy; in our study we highlight a four-factor structure, rather than five as in the original study and in the Chinese version. The factor that is not confirmed in our study is Appreciation of life's meanings. In addition, some items were loaded onto different factors compared with the original version.

The items related to Appreciation of life's meanings ("Helps me find personal meaning in my experiences", "Encourages me to see others' perspectives about life", and "Helps me to understand the spiritual dimensions of life") were loaded in Supportive learning climate. The possible explanation is that the tutorial style and learning methods in Italy direct the phenomenon of care and the idea of human caring through characteristic traits of good care, such as paying attention to others, to feel empathic about the presence and the emotions "Dasein" [47], observing a respectful silence when faced with anguish, in addition to considering the spiritual dimension.

The factor Supportive learning climate explains the highest percentage of variability and includes 12 items: six items ("Acknowledge his or her own limitations or mistakes", "Clearly communicates his or her expectations", "Serves as a trusted resource for personal

Table 4 Mean, sd, median and lqr of NSPIC by sex, university, and junior and senior students

\begin{tabular}{lcclcc}
\hline & Mean & Sd & Median & Iqr & $P$-value \\
\hline Sex & & & & & \\
M & 118.17 & 18.37 & 117.5 & 17 & $0.0326^{*}$ \\
F & 112.46 & 19.13 & 114 & 20 & \\
University & & & & & \\
$\quad$ Pavia & 120 & 20.06 & 118 & 16 & $0.0001^{* *}$ \\
$\quad$ Rome Biomedico Campus & 109.77 & 15.81 & 110.5 & 19 & \\
$\quad$ Rome Tor Vergata & 111.70 & 20.81 & 116 & 14 & \\
Education & & & & & \\
$\quad$ Junior (I - II years) & 112.46 & 14.31 & 114 & 17 & $0.0253^{*}$ \\
$\quad$ Senior (III year) & 116.18 & 26.59 & 118 & 24 & \\
\hline
\end{tabular}

*Mann Whitney U test

**Kruskall Wallis test
Table 5 Reliability: Cronbach's alpha values for NSPIC and its subscale

\begin{tabular}{ll}
\hline & Cronbach's alpha \\
\hline NSPIC & 0.94 \\
Supportive learning climate & 0.95 \\
Instills confidence through caring & 0.93 \\
Respectful sharing & 0.83 \\
Control vs flexibility & 0.69 \\
\hline
\end{tabular}

problem-solving", "Offers support during stressful times, Accepts my negative feelings, while helping me to see the positive", "Allows me to express my true feelings") are the same as in the original version; three items were loaded from Appreciation of life's meanings and three items from Instill confidence through caring ("Instills in me a sense of hopefulness for the future", "Cares about me as a person", and "Inspires me to continue the development of knowledge and skills"). We think that in the student's mind there is no clear subdivision of these three domains (Supportive learning climate, Appreciation of life's meanings, Instill confidence through caring), moreover, the Italian nursing education does not orient the student to understand the appreciation of life's meanings and the student converts these items into one domain "Supportive learning climate". These differences are mainly determinated by the caring instructor style adopted in the clinical training and its perception among students [5]. In the Italian culture, the tutorial style refers not only to the student's cognitive processes, but also to the person in its entirety $[48,49]$.

In fact, as Watson states [50], learning is much more than just acquiring information, facts or data; it implies a meaningful and trusting relationship which is intersubjective. The nature of the relationship, along with the learning form and context, influences the process and demands respect for the individual. In fact, caring interactions between teachers and students reflect the very nature of the professional-client relationship [28]. As Wade and Kasper [27] maintain, nursing students perceptions of their instructors caring can reveal the often unapparent aspects of how nursing students learn to care for their patients. If students perceive an educational climate based on caring, they learn to become professionals.

The factor Instill confidence through caring includes seven items: four items ("Shows genuine interest in patients and their care", "Displays kindness to me and others", "Makes me feel that I can be successful", "Helps me envision myself as a professional nurse") are the same as in the original version; two items ("Respects me as a unique individual" and "Is attentive to me when we communicate") were loaded from Respectful sharing; and one item was loaded from Supportive learning climate ("Makes herself/himself available to me"). A possible 
explanation could be the theoretical assumptions of the andragogy that is well-outlined by Knowless [51] and analyzed in a book in Italian by Franco Angeli, who represents an important reference point for Italian nursing education culture from the 1990s.

The factor, Respectful Sharing, includes seven items. In this case only one item is the same as in the original version (12 Does not reveal any of his or her personal side). The remaining items ("Makes me feel like a failure", "Does not believe in me", "Makes me nervous in the clinical laboratory", and "Does not trust my judgment in the clinical laboratory") were loaded from Instill confidence through caring and from Supportive learning climate ("Discourages independent problem solving" and "Seems caught up in her/his own priorities rather than responding to my needs"). This result expresses the experience of students who see the importance of instilling respect in the relationship with the clinical tutor. Dynamics probably occur in the relationship between student and clinical tutor, not only at the professional level but the personal one as well, and the student feels it is important to also share personal information with the tutor if this is appropriate and relevant for clinical learning, a factor that has been reported by several authors $[15,20,21,24,26]$.

The factor Control vs Flexibility confirms the original version but includes an other item: "Inappropriately discloses personal information about me to others" loaded from Supportive Learnig climate. In EFA, this last item had a factor loading smaller than the a priori determined cutoff, but we decided to preserve it in the final questionnaire version because it contributed to construct a factor's internal reliability.

In the student's mind this behavior of caring instructors is experienced as an element of rigidity rather than as an element of supportive learning. We think that this attitude of instructors caring is perceived by the student as a prejudice that may influence the student's evaluation process [52].

In other studies as well from other countries [33, 50, 53] with different cultures, which assessed instruments in nursing education, differences have emerged in the factors or the items contained in the model. These results support the explanations in our study.

The inspection of I-NSPIC's median score revealed that senior students perceived their instructors as caring more than junior students did (median score 118 vs 114 respectively, $p=0.0253$ ). Probably senior students perceived their instructors significantly more positively because they have a complete academic experience; therefore they are more confident and aware, unlike junior students who are living in a period of continuous transition. Perhaps the one-to-one relationship in the third year promotes a privileged relationship that improves the interpersonal relationship and facilitates caring and socialization in the profession. In our study, the mean score of the I-NSPIC (113.63) is smaller than the Chinese version C-NSPIC (150.03); therefore the internal consistency of the four factors, except for Control vs flexibility, is higher with respect to the C-NSPIC.

\section{Study limitations}

We are aware that our study has some limitations. In this study, we used EFA for exploring the relationships among the variables and we does not have an a priori fixed number of factors; a CFA tests whether a known factor model can predict a set of observed data [54]. Researchers use CFA to verify or confirm hypotheses or theory $[55,56]$. In our case, we performed only EFA because we focused our attention on cultural context differences, in fact, our result does not confirm original structure questionnaire. Therefore, our actual work is obtaining more data to implement CFA to confirm or reject the measurement theory get out in this work. Furthermore, in our sample there is no homogenous distribution of males and females (females $80.78 \%$ ), and thus it is hard to perform subgroup analyses. In addition, the study has a limited geographical representativeness with regard to Italian nursing students (Central and Northern Italy); the participants were limited to nursing students in degree nursing programs. In our opinion, it would be important to know the perception of instructor caring also in diverse several samples such as master's degree nursing programs and with a sample representing all Italian geographic areas.

\section{Conclusions}

This is the first study to evaluate the psychometric properties of NSPIC in Italy; we have showed that the INSPIC has satisfactory reliability and validity. Unlike what is found in the literature $[27,33]$, our questionnaire presents a four-dimensional structure. We conclude that the I-NSPIC is an effective and valid instrument for assessing the perception of instructor caring in Italian undergraduate nursing students; furthermore it may also prove helpful in promoting the caring ability of nursing students and in increasing the caring interactions in the relationship between instructor and nursing students.

Regarding future research, we feel it is fundamental to use the I-NSPIC questionnaire at the end of each clinical internship that lasts an entire academic year, so as to identify strengths and urgent issues to address regarding the individual tutors in the various internship areas. Moreover, future validation research can expand these findings by testing the psychometric properties of the I-NSPIC on a larger sample from several universities distributed throughout the country, north, centre and sud Italy. 


\section{Additional files}

Additional file 1: Questionario "Le percezioni degli studenti infermieri del rapporto con il tutor clinico" (I-NSPIC). (DOCX 27 kb)

Additional file 2: Questionario "Clinical Learning Environment and Supervision plus Nurse Teacher Scale" (CLES-T). (DOC 77 kb)

\section{Abbreviations}

C- NSPIC: Chinese version of the Nursing Students' Perception of Instructor Caring; CLES-T: Clinical Learning Environment and Supervision plus nurse Teacher scale; EFA: Exploratory Factor Analysis; ICC: Intraclass correlation coefficient; I-NSPIC: Italian version of the Nursing Students' Perception of Instructor Caring; NSPIC: Nursing Students' Perception of Instructor Caring

\section{Acknowledgements}

We thank G. Wade and N. Kasper for giving us the permission to use their questionnaire, and we also thank Robert Ponzini for language editing as well as the students who participated in this study. We thank the Reviewers Dr. Melih Elcin and Dr. Sherry Dahke for their preciouses suggestions that helped us to improve our manuscript.

\section{Funding}

This research has not received any specific grant from funding agencies in the public, commercial, or not-for-profit sectors.

\section{Availability of data and materials}

The Italian version of datasets generated and analyzed during the current study are available from the corresponding author on reasonable request.

\section{Authors' contributions}

CA, MGDM, AMG and MP contributed to the original conception and the development of the Study. CA, AMG, LC, EF, EV and RA performed the data collection. MP and PB performed data analysis. CA, AMG, MP and PB contributed to the final version of the paper. CA supervised the study. All the authors read and approved the final manuscript.

\section{Authors' information}

Cristina Arrigoni

Degrees and certification: Masters Degree in Educational Sciences, Università Cattolica del Sacro Cuore of Milan, Italy \& Post Graduate Courses in Health Education and design, University of Pavia, Faculty of Medicine and Surgery. Mariangela Puci

Degrees and certification: Masters Degree in Nursing and Midwifery Science, University of Pavia.

Anna Maria Grugnetti

Degrees and certification: Masters Degree in Nursing and Midwifery Science, University of Pavia \& Ph.D in Nursing Research, Faculty of Health Science, University of Genoa, Italy.

Lucia Collivasone

Degrees and certification: Masters Degree in Nursing and Midwifery Science, University of Pavia.

Elisa Fenizia

Degrees and certification: Master Degree in Nursing and Midwifery, Tor Vergata University Rome.

Paola Borrelli

Degrees and certification: PhD-equivalent in Medical Statistics, School of Medical Statistics \& PhD in Public Health and Education, School of Public Health, University of Pavia, Pavia, Italy.

Ercole Vellone

Degrees and certification: PhD Nursing Science Tor Vergata University, Rome. Rosaria Alvaro

Degrees and certification: Master Degree in Nursing Sciences and Midwifery, Tor Vergata University, Rome.

Michela Piredda

Degrees and certification: PhD Nursing Science Tor Vergata University, Master in Nursing Science Tor Vergata University, Master in Nursing Research King's College University of London, Master Degree in Biology University of Palermo, Registered Nurse University of Navarra, Spain.

Maria Grazia De Marinis
Degrees and certification: Masters Degree in Education Sciences, Sapienza University of Rome, Italy. Masters Degree in Nursing, Faculty of Health Sciences, University of Rome Tor Vergata, Italy.

\section{Ethics approval and consent to participate}

This study was given written approval by the University Academic Commettee. Students are not required written consent, since consent was implicit in filling out the questionnaire.

The students received detailed information about the purpose and methods of the study and anonymity was guaranteed. The students were also informed that the data would be confidential and they would have been collected and analyzed anonymously. Participation was voluntary. Students were reassured regarding the lack of participation in the study would have no impact on their training.

\section{Consent for publication}

Not applicable.

\section{Competing interests}

The authors of this manuscript declare that they have no competing interests as defined by the Editorial Policy of BMC Medical Education. Moreother they have no other interests that may have influenced the results and the discussion of this paper.

\section{Publisher's Note}

Springer Nature remains neutral with regard to jurisdictional claims in published maps and institutional affiliations.

\section{Author details}

${ }^{1}$ Department of Public Health, Experimental and Forensic Medicine, Unit of Hygiene, University of Pavia, Via Forlanini, 2-27100 Pavia, Italy. Department of Public Health, Experimental and Forensic Medicine, Unit of Biostatistics and Clinical Epidemiology, University of Pavia, Via Forlanini, 2-27100 Pavia, Italy. ${ }^{3}$ IRCCS Policlinic San Matteo Foundation Pavia, Via Forlanini, 2-27100 Pavia, Italy. ${ }^{4}$ Azienda Ospedaliera di Pavia, Corso Milano, 19, Vigevano, Pavia, Italy. ${ }^{5}$ Tor Vergata University, Faculty of Medicine, Via Montpellier, 1, 00133 Rome, Italy. ${ }^{6}$ Research Unit Nursing Science, Campus Bio-Medico di Roma University, Via Alvaro del Portillo, 21-00128 Rome, Italy.

Received: 3 March 2017 Accepted: 31 October 2017

Published online: 17 November 2017

\section{References}

1. Dunn SV, Burnett P. The development of a clinical learning environment scale. J Adv Nurs. 1995;22(6):1166-73.

2. Chan D. Development of the clinical learning environment inventory: using the theoretical framework of learning environment studies to assess nursing students' perceptions of the hospital as a learning environment. J Nurs Educ. 2002;41(2):69-75.

3. Henderson A, Twentyman M, Heel A, Lloyd B. Students' perception of the psycho-social clinical learning environment: an evaluation of placement models. Nurse Educ Today. 2006;26(7):564-71.

4. Karayurt $\mathrm{O}, \mathrm{Mert} \mathrm{H}$, Beser $\mathrm{A}$. A study on development of a scale to assess nursing students' performance in clinical settings. J Clin Nurs. 2009;18(8):1123-30.

5. Tomietto M, Saiani L, Palese A, Cunico L, Cicolini G, Watson P, Saarikoski M. Clinical learning environment and supervision plus nurse teacher (CLES+T) scale: testing the psychometric characteristics of the Italian version. $\mathrm{G}$ Ital Med Lav Ergon. 2012;34(2):B72-80.

6. Bisholt B, Ohlsson U, Engström A, Johansson A, Gustafsson M. Nursing students' assessment of the learning environment in different clinical settings. Nurse Educ Pract. 2014;14(3):304-10.

7. Arrigoni C, Grugnetti AM, Caruso R, Gallotti ML, Borrelli P, Puci M. Nursing students' clinical competencies: a survey on clinical education objectives. Ann lg. 2017:29(3):179-88.

8. Labrague LJ, McEnroe-Petitte DM, Papathanasiou IV, Edet OB, Arulappan J. Impact of instructors' caring on students' perceptions of their own caring behaviors. J Nurs Scholarsh. 2015;47(4):338-46.

9. Benner $P$, Wrubel J. The primacy of caring: stress and coping in health and illness. Menlo Park: Addison-Wesley Publishing; 1989.

10. Leininger $\mathrm{M}$, Watson J. The caring imperative in education. New York: National League of Nursing; 1990 
11. Watson J. Assessing and measuring caring in nursing and health science. 2nd ed. New York: Springer; 2008.

12. Smith MC. Caring and the science of unitary human beings. Adv Nurs Sci. 1999;21(4):14-28.

13. Watson J, Smith MC. Caring science and the science of unitary human beings: a trans-theoretical discourse for nursing knowledge development. J Adv Nurs. 2002;37(5):452-61.

14. Watson J, Foster R. The attending nurse caring model: integrating theory, evidence and advanced caring-healing therapeutics for transforming professional practice. J Clin Nurs. 2003;12(3):360-5

15. Gillespie M. Student-teacher connection in clinical nursing education. J Adv Nurs. 2002;37(6):566-76.

16. Carlson E, Christine W, Ewa P. Teaching during clinical practice: strategies and techniques used by preceptors in nursing education. Nurse Educ Today. 2009:29(5):522-6.

17. Kristofferzon ML, Mårtensson G, Mamhidir A, Löfmark A. Nursing students' perceptions of clinical supervision: the contributions of preceptors, head preceptors and clinical lecturers. Nurse Educ Today. 2013;33(10):1252-7.

18. Usher K, Nolan C, Reser P, Owens J, Tollefson J. An exploration of the preceptor role: preceptors' perceptions of benefits, rewards, supports and commitment to the preceptor role. J Adv Nurs. 1999;29(2):506-14.

19. Lillibridge J. Using clinical nurses as preceptors to teach leadership and management to senior nursing students: a qualitative descriptive study. Nurse Educ Pract. 2007;7(1):44-52

20. McClure $E$, Black $L$. The role of the clinical preceptor: an integrative literature review. J Nurs Educ. 2013;52(6):335-41.

21. Trede F, Sutton K, Bernoth M. Conceptualisations and perceptions of the nurse preceptor's role: a scoping review. Nurse Educ Today. 2016;36:268-74.

22. Altmann TK. Preceptor selection, orientation, and evaluation in baccalaureate nursing. Education. Int J Nurs Educ Scholarsh. 2006;3:1-16.

23. Luhanga LF, Billay D, Grundy Q, Myrick F, Yonge O. The one-to-one relationship: is it really key to an effective Preceptorship experience? A review of the literature. Int J Nurs Educ Scholarsh. 2010;7(1):1-15.

24. Saarikoski $M$, Leino-Kilpi $H$. The clinical learning environment and supervision by staff nurses: developing the instrument. Int J Nurs Stud. 2002; 39(3):259-67.

25. Hosoda Y. Development and testing of a clinical learning environment diagnostic inventory for baccalaureate nursing students. J Adv Nurs. 2006; 56(5):480-90.

26. Brammer J. A phenomenographic study of registered nurses' understanding of their role in student learning-an Australian perspective. Int J Nurs Stud. 2006;43(8):963-73.

27. Wade G, Kasper N. Nursing students' perceptions of instructor caring: an instrument based on Watson's theory of transpersonal caring. J Nurs Educ. 2006;45(5):162-8.

28. Watson J. Human caring as moral context for nursing education. Nurs Health Care. 1988;9(8):422-5.

29. Saarikoski M, Isoaho H, Warne T, Leino-Kilpi H. The nurse teacher in clinical practice: developing the new sub-dimension to the clinical learning environment and supervision (CLES) scale. Int J Nurs Stud. 2008;45(8):1233-7.

30. Arrigoni C, Miazza D, Gerra MT. Prevention in the workplace and training of personnel: new methodological approaches. J Prev Med Hyg. 2012;16(1):33-9.

31. Lovecchio CP, Di Mattio MJ, Hudacek S. Predictors of undergraduate nursing student satisfaction with clinical learning environment: a secondary analysis. Nurs Educ Perspect. 2015;36(4):252-4.

32. Arrigoni $C$, Micheletti $P$, Grugnetti AM, Ferrari $P$, Borrelli $P$, Montomoli $C$, Pelissero $G$. The students' reasons to choose a nursing degree program: an Italian exploratory study. Ann lg. 2014;26(6):570-7.

33. Li J, Zhou L, Zhu D, Hu C, Zhang X, Xu Y. Chinese version of the nursing students' perception of instructor caring (C-NSPIC): assessment of reliability and validity. Nurse Educ Today. 2013;33(12):1482-9.

34. Zamanzadeh V, Valizadeh L, Azimzadeh R, Aminaie N, Yousefzadeh S. First and fourth-year student's perceptions about importance of nursing care behaviors: socialization toward caring. J Caring Sci. 2014;3(2):93-101.

35. Beaton DE, Bombardier C, Guillemin F, Ferraz MB. Guidelines for the process of cross-cultural adaptation of self-report measures. Spine (Phila Pa 1976). 2000;25(24):3186-91.

36. MacCallum RC, Widaman KF, Zhang S, Hong S. Sample size in factor analysis. Psychol Methods. 1999;4:84-99.

37. Everitt B. Multivariate analysis: the need for data, and other problems. Br J Psychiatry. 1975;126(3):237-40.
38. Bartholomew D. Latent variable models and factor analysis. New York Oxford University Press; 1987.

39. Guttman L. Some necessary conditions for common-factor analysis. Psychometrika. 1954;19(2):49-161.

40. Kaiser HF. The application of electronic computers to factor analysis. Educ Psychol Meas. 1960;20(1):141-51.

41. Kaiser HF. A second generation little jiffy. Psychometrika. 1970;35(4):401-15.

42. Cattell RB. The Scree test for the number of factors. Multivar Behav Res. 1966:1(2):245-76.

43. Lewis-Beck MS. Factor analysis and related techniques. London: Sage; 1994.

44. Costello A, Osborne J. Best practices in exploratory factor analysis: four recommendations for getting the most from your analysis. PARE. 2005;10(7):1-9.

45. Cronbach $\amalg$. Coefficient alpha and the internal structure of tests. Psychometrika. 1951;16(3):297-334.

46. Bartko JJ. The intraclass correlation coefficient as a measure of reliability. Psychol Rep. 1966;19(1):3-11

47. Being HM, Time A. Translated by Joan Stambaugh. Albany: State University of New York Press; 1996

48. Binetti P, Pontalti I, Santini D. II Tutorato, Modelli ed esperienze nella didattica universitaria. Roma: Società Editirice Universo; 1996. p. 46.

49. Brugnolli A, Saiani L, Palese A. Percezione degli studenti infermieri delle strategie tutoriali nell'apprendimento clinico. Tutor. 2008:8(3):124-31.

50. Watson J, Sironi C. Assistenza infermieristica. Milano: Cea; 2013.

51. Knowles M, Holton EF, Swanson RA. The adult learner: the definitive classic in adult education and human resource development. 7th ed. New York: Routledge; 2012.

52. Zannini L, Randon G, Saiani L. The contribution of clinical approaches to qualitative research on hidden curriculum a participative research with a sample of Italian nursing faculty. Medic. 2016;24(1):53-65.

53. Fisher MJ, King J. The self-directed learning readiness scale for nursing education revisited: a confirmatory factor analysis. Nurse Educ Today. 2010;30(1):44-8

54. DeCoster J. Overview of Factor Analysis. 1998. Retrieved from http://stathelp.com/factor.pdf. Accessed 24 Mar 2015.

55. Ruscio J, Roche B. Determining the number of factors to retain in an exploratory factor analysis using. Pract Assess Res Eval. 2012;18(8):14. Courtney; EFA Factors using SPSS \& $R$

56. Schmitt TA. Current methodological considerations in exploratory and confirmatory factor analysis. J Psychoeduc Assess. 2011:29(4):304-21.

\section{Submit your next manuscript to BioMed Central and we will help you at every step:}

- We accept pre-submission inquiries

- Our selector tool helps you to find the most relevant journal

- We provide round the clock customer support

- Convenient online submission

- Thorough peer review

- Inclusion in PubMed and all major indexing services

- Maximum visibility for your research

Submit your manuscript at www.biomedcentral.com/submit

Biomed Central 